\title{
Genişlemiş Spektrumlu Beta-laktamaz Üreten Escherichia coli ve Klebsiella pneumoniae Suşlarında Piperasilin/Tazobaktam İnvitro Etkinliği
}

Özlem AYDEMIR ${ }^{1}$, Hüseyin Agah TERZİ ${ }^{1}$, Elif ŞAHIN ÖZÖZEN² ${ }^{2}$, Mehmet KÖROĞLU² $^{2}$ Mustafa ALTINDİŞ²

\begin{abstract}
Öz
Piperasilin-tazobaktam (TZP), genişletilmiş spektrumlu beta-laktamaz (GSBL) üreten Gramnegatif bakterilerin neden olduğu enfeksiyonların tedavisi için sıklıkla tercih edilen bir ajandır. Bununla birlikte, GSBL üreten bakterilerin neden olduğu ciddi enfeksiyonlara Piperasilin-tazobaktamın etkinliği hakkında tartışmalar vardır. Bu çalışmada, laboratuvara gönderilen örneklerden izole edilen GSBL pozitif bakterilerde TZP'nin etkinliğini belirlemeyi amaçladık. Servis ve poliklinik hastalarına ait kan, idrar, yara, trakeal aspirat örneklerinden izole edilen 548 GSBL pozitif Escherichia coli ve Klebsiella pneumoniae suşu çalışmaya dahil edildi. Bakteri tanımlaması, antibiyotik duyarlılık testleri ve GSBL tespitinde VITEK $2^{\circledR}$ otomatize sistemi kullanıldı. Çalışmamıza dahil edilen izolatların 307'si (\%56) E. coli, 241'i $(\% 43,9)$ K. pneumoniae suşu idi. İzolatların TZP direnç oranları incelendiğinde; $E$. coli suşlarında TZP direnç oranı $\% 44,6$ olarak saptanırken en yüksek direnç \%47,6 ile trakeal aspirat örneklerinde saptand. K. peumoniae suşlarında ise TZP direnç oran $1 \% 41$ olarak bulundu. GSBL pozitif bakterilerin neden olduğu enfeksiyonlarda TZP'nin etkinliğini gösteren yeterli çalışma bulunmamakla birlikte, mevcut çalışmalar bu antibiyotiklerin etkinliğinin enfeksiyon bölgesine ve şiddetine göre değiştiğini göstermektedir. PRP sonuç bildirimi ile ilgili CLSI ve EUCAST arasında bir fikir birliği yoktur. Bu nedenle, bu konuda daha kapsamlı bir çalışmaya ve TZP'nin sonuç raporunun yeniden değerlendirilmesine ihtiyaç vardır.
\end{abstract}

Anahtar Kelimeler: Piperasilin-tazobaktam, genişlemiş spektrumlu beta-laktamaz, Escherichia coli, Klebsiella pneumoniae
Yayın Bilgisi

Gönderi Tarihi: 05.11.2018

Kabul Tarihi:04.02.2019

Online Yayın Tarihi:30.06.2019

DOI: $10.26453 /$ otjhs. 487008

Sorumlu Yazar

Özlem AYDEMIR

Sağlık Bakanlığı Sakarya

Üniversitesi Eğitim ve Araştırma

Hastanesi, Trbbi Mikrobiyoloji

Laboratuvarı, Sakarya, TÜRKIYE

Tel : +90 5056369400

Faks : +902642759192

e-Mail: akkozlem@hotmail.com

\section{Piperacillin / Tazobactam In-vitro Activity in Escherichia coli and Klebsiella pneumoniae Strains with}

\section{Extended Spectrum Beta-Lactamase Production}

Özlem AYDEMIRR ${ }^{1}$, Hüseyin Agah TERZi் ${ }^{1}$, Elif ŞAHİ ÖZÖZEN ${ }^{2}$, Mehmet KÖROĞLU $^{2}$, Mustafa ALTINDİ̧̧²

\begin{tabular}{|c|c|}
\hline Abstract & Article Info \\
\hline Piperacillin-tazobactam (TZP) is a frequently preferred agent for the treatment of infections & Received:05.11.2018 \\
\hline However, there are some controversies about the efficacy of Piperacillin-tazobactam in & Accepted:04.02.2019 \\
\hline severe infections caused by ESBL producing bacteria. In this study, we aimed to determine & Online Published:30.06.2019 \\
\hline laboratory. Our medical microbiology laboratory included 548 ESBL producing Escherichia & DOI: $10.26453 /$ otjhs. 487008 \\
\hline 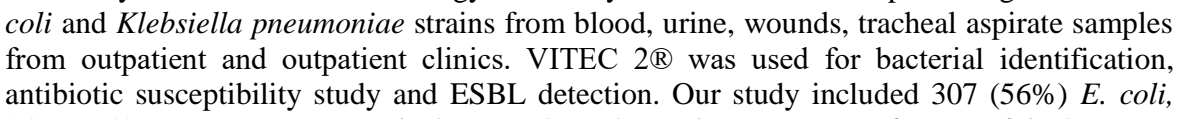 & \\
\hline $\begin{array}{l}241(\% 43.9) K \text {. pneumoniae isolates. When the resistance rates of TZP of isolates are } \\
\text { examined; The resistance rate of TZP in } E \text {. coli strains was } 44.6 \% \text { and the highest resistance }\end{array}$ & Corresponding Author \\
\hline was detected in tracheal aspirates with $47.6 \%$. In K. peumoniae strains, the resistance rate of & Özlem AYDEMİR \\
\hline TZP was found to be $41 \%$. While there are not enough studies showing the efficacy of TZP & Sağlık Bakanlığı Sakarya Üniversitesi \\
\hline these antibiotics changes according to infection site and severity. There is no consensus & Eğitim ve Araştırma Hastanesi, Tıbbi \\
\hline $\begin{array}{l}\text { between CLSI and EUCAST regarding the TZP result notification. Therefore, there is a need } \\
\text { for more extensive work in this regard and a reevaluation of the outcome report of the TZP. }\end{array}$ & Mikrobiyoloji Laboratuvarı, Sakarya, \\
\hline Keywords: Piperacillin-tazobactam, extended spectrum beta-lactamases, Escherichia coli, & TÜRKIYYE \\
\hline Klebs & Tel : +90 5056369400 \\
\hline & Faks : +902642759192 \\
\hline & e-Mail: akkozlem@hotmail.com \\
\hline
\end{tabular}


${ }^{1}$ Sağlık Bakanlığı Sakarya Üniversitesi Eğitim ve Araştırma Hastanesi, Tibbi Mikrobiyoloji Laboratuvarı, Sakarya

${ }^{2}$ Sakarya Sakarya Üniversitesi, Tıp Fakültesi, Tıbbi Mikrobiyoloji Anabilim Dalı, Sakarya

\section{GİRIŞ}

Genişlemiş spektrumlu beta laktamazlar (GSBL); penisilinler, ileri kuşak sefalosporinler ve aztreonam dahil olmak üzere çoğu betalaktam antibiyotikleri hidrolize eden enzimlerdir. GSBL pozitif bakteriler, özellikle üçüncü kuşak sefalosporinlerin yaygın kullanımı sonucu ortaya çıkmışlardır. Başlangıçta sadece hastanede yatan hastalarda karşımıza çıkarken son yıllarda ayaktan hastalarda da sıklıkla rastlanılmaktadır. ${ }^{1}$

GSBL üreten Enterobacteriaceae türleri, kişi ve toplum sağlığı üzerinde ciddi sorun oluşturan yaygin insan patojenleridir. GSBL pozitif Enterobacteriaceae türlerinin neden olduğu enfeksiyonlarda, en güvenli ve en etkili tedavinin nasıl yapılacağı konusunda yeterli çalışma bulunmamaktadır. Ancak GSBL pozitif bakterilerin yol açtığı enfeksiyonlarda genellikle piperasilin/tazobaktam gibi beta-laktamaz inhibitörleri, sefamisinler, sefepim ve aminoglikozid grubu antibiyotikler kullanılmakta olup, ilk seçenek karbapenemlerdir. ${ }^{2}$ Buna bağlı olarak son yıllarda karbapenem direncinde de artış gözlenmiştir. $^{3} \mathrm{Bu}$ nedenle bu bakterilere bağlı gelişen enfeksiyonların tedavisinde TZP'nin etkinliği tekrar değerlendirilmeye başlanmıştır. ${ }^{3}$
Ancak yapılan bazı çalışmalarda piperasilin/tazobaktam kombinasyonunun etkinliğinin $\quad$ yetersiz kalabileceği bildirilmektedir. Klinik Laboratuar Standartları Enstitüsü (CLSI), TZP duyarlılığını GSBL durumuna bakılmaksızın test edildiği şekliyle raporlanmasını önermektedir. Ancak Avrupa Antimikrobik Duyarlılık Komitesi (EUCAST); TZP'ye duyarlı iken 3. kuşak sefalosporinlere dirençli bulunan bakteriler için üriner sistem enfeksiyonları haricindeki durumlarda TZP etkinliği konusunda klinik belirsizlik olduğu yönündeki uyarının eklenmesini önermektedir. ${ }^{4,5}$

$\mathrm{Bu}$ çalışmada, laboratuvarımıza gönderilen çeşitli klinik örneklerden izole edilen GSBL pozitif E. coli ve $K$. pneumoniae suşlarına karş1 TZP'nin invitro etkinliğinin araştırılması amaçlanmıştır.

\section{MATERYAL VE METOT}

Hastanemiz tıbbi mikrobiyoloji laboratuvarına gönderilen servis ve poliklinik hastalarına ait kan, idrar, yara, trakeal aspirat örneklerinden izole edilen 548 GSBL pozitif Escherichia coli ve Klebsiella pneumoniae suşunun antibiyotik duyarlılık sonuçları retrospektif olarak tarandı. Çalışmamız için Sakarya Üniversitesi Tıp Fakültesi etik kurulundan 
71522473/050.01.04/324 say1l1, 03/01/2019 tarihli etik kurul onayı alınmıştır. Suşların tanımlaması, antibiyotik duyarlılık testleri ve GSBL tespiti VITTEK $2^{\circledR}$ (Biomerieux, Marcy I'Etoile, Fransa) otomatize sistemi ile yapild1. TZP için MIK değerleri; $\leq 16 / 4$ ise duyarlı, 32/4$64 / 4$ ise orta duyarl1, $\geq 128 / 4$ ise dirençli olarak kabul edildi. Orta duyarlılar dirençli olarak kabul edildi. Karbapenemlerden imipenem ve meropenem için MİK değerleri; $\leq 1$ ise duyarl, $\geq 4$ ise dirençli; ertapenem için $\leq 0,5$ ise duyarlı, $\geq 1$ ise dirençli olarak kabul edildi. Ayrıca GSBL pozitifliği CLSI kriterleri doğrultusunda çiftdisk sinerji yöntemiyle araştırıldı. Çift-disk sinerji yöntemi; sefotaksim, seftazidim ve amoksisilin-klavulanat diskleri kullanılarak yapıldı. Bunun için Mueller Hinton Agar besiyeri üzerine merkezde amoksisilin-klavulanik asit (20/10 $\mu g)(A M C)$ olmak üzere çevresine disk merkezleri arası uzaklık $25 \mathrm{~mm}$ olacak şekilde seftazidim (10 $\mu \mathrm{g})(\mathrm{CAZ})$, seftriakson $(30 \mu \mathrm{g})(\mathrm{CRO})$, sefotaksim (5 $\mu \mathrm{g})(\mathrm{CTX})$ ve aztreonam $(30 \mu \mathrm{g})(\mathrm{ATM})$ diskleri yerleştirildi. Plakların $35-37{ }^{\circ} \mathrm{C}$ 'de $18-24$ saatlik inkübasyonundan sonra CAZ, CRO, CTX ve ATM diskleri çevresindeki inhibisyon zonunun AMC diskine doğru $\geq 5 \mathrm{~cm}$ genişlemesi ve/veya iki inhibisyon zonu arasında bakteri üreyen alanlarda üreme olmayan bir bölgenin varlığ ile GSBL üretiminin olduğuna karar verildi.

\section{BULGULAR}

Çalışmamıza dahil edilen izolatların 307'si (\%56) E. coli, 241'i $(\% 43,9) K$. pneumoniae suşu idi. E. coli suşlarının 189'u $(\% 61,5)$ idrar örneklerinden, 54’ü (\%17.5) kan örneklerinden izole edilirken, bunları yara ve steril vücut sıv1 örnekleri (\%14) ile trakeal aspirat örnekleri (\%6.8) takip etti. $K$. pneumoniae suşlarının 137'si $(\% 56,8)$ idrar, 31'i $(\% 12,8)$ kan örneklerinden izole edilirken bunları yara ve steril vücut sıv1 örnekleri $(\% 19,9)$ ile trakeal aspirat örnekleri $(\% 10,3)$ takip etti. Suşların izole edildikleri örneklere göre dağılımı Tablo 1 'de verilmiştir.

İzolatların TZP direnç oranları incelendiğinde; E. coli suşlarında TZP direnç oranı \%44,6 olarak saptanırken en yüksek direnç \%47,6 ile trakeal aspirat örneklerinde saptand1. Bunu sırası ile idrar, yara ve steril vücut sıvı örnekleri ile kan örnekleri takip etti. $K$. peumoniae suşlarında ise TZP direnç oranı \%41 olarak bulundu. Örneklere göre dağılımı incelendiğinde ise en yüksek direnç yine \%44 ile trakeal aspirat örneklerinde saptanırken bunu idrar, kan ve yara/steril vücut sıvı örnekleri takip etti. Suşların TZP direnç oranları Tablo 1' de verilmiştir.

GSBL pozitif, suşların karbapenem direnç oranları değerlendirildiğinde; $K$. pneumoniae suşlarının 17' sinde (\%7) imipenem, 18'inde $(\% 7,4)$ meropenem, $17^{\prime}$ sinde $(\% 7)$ ertapenem 
direnci saptandı. E. coli suşlarının 42'inde $(\% 13,6)$ imipenem, $26(\% 8,4)$ 'sinda ertapenem direnci olduğu görüldü (Tablo 2).

\section{TARTIŞMA VE SONUÇ}

GSBL pozitif bakterilerde TZP duyarlılık sonuçlarının bildiriminde laboratuvarlar arasında farklılıklar bulunmaktadır. Bazı laboratuvarlar TZP bildirimini hiç yapmazken bazı laboratuvarlar MİK değerlerine yetersiz tedavi olasılığı yorumunu ekleyerek bildirim yapmaktadır. ${ }^{6}$ Literatürden elde edilen verilere göre TZP etkinliği enfeksiyonun türüne göre değiştiği için sonuç bildiriminin yeniden değerlendirilmesi gerektiği gündeme gelmiştir. ${ }^{6}$ Seo ve ark. TZP için MİK değeri bildiriminin tedaviyi yönlendirmede etkili olacağını bildirmişleridir. ${ }^{1,7}$ GSBL pozitifliği durumunda, TZP sonuçları duyarlı bildirilmesine rağmen çoğu klinisyen bu tür enfeksiyonlarda TZP tedavisine şüphe ile yaklaşmakta ve tedavide karbapenemleri tercih etmektedirler. ${ }^{8}$ Bazı laboratuvarlar, tüm GSBL üreten Enterobacteriaceae izolatlarının sebep olduğu kan dolaşımı yolu enfeksiyonlarında, invitro duyarlı olarak saptanan TZP dirençli olarak bildirmektedir. $^{3} \quad$ GSBL enzimleri, karbapenemleri hidrolize edememektedirler. $\mathrm{Bu}$ nedenle karbapenemler GSBL üreten bakterilerin neden olduğu invaziv enfeksiyonların tedavisinde, tercih edilen ajanlar olmaktadır. Ancak karbapenem kullanılmasına bağlı gelişen karbapenem direnci de çözülmesi gereken bir sorun haline gelmiştir. ${ }^{2} \mathrm{Bu}$ nedenle son yıllarda klinisyen ve laboratuvar uzmanları tarafından GSBL üreten gram negatif bakterilerin neden olduğu enfeksiyonlarda betalaktam/beta-laktamaz inhibitör (BLBLI) kombinasyonlarının kullanımı sıklıkla gündeme gelmektedir. $^{5} \quad$ Özellikle TZP kullanımına yönelik çalışmalar giderek önem kazanmaktadir. ${ }^{5}$

GSBL pozitif bakterilerin neden olduğu üriner sistem enfeksiyonlarında TZP'nin etkinliğini değerlendiren çalışmalar bu ilacın etkili bir tedavi seçeneği olabileceğini bildirmişlerdir. ${ }^{1,2}$ Buna ilaveten TZP, ertapenem ve sefepimin etkinliğini karşılaştıran bir çalışmada GSBL üreten $E$. coli'nin neden olduğu üriner sistem enfeksiyonlarında TZP'nin etkin bir tedavi sağlayacağı belirtilmiştir. Bu çalışmada hastalar 3 gruba ayrılmış ve çalışma sonunda TZP ve ertapenem (sirasiyla; \%93,9, \%97,0) tedavisinin etkinlikleri açısından anlamlı bir fark bulunmazken, sefepim alan hastalarda tedavi başarı oranı $\% 33,3^{\prime}$ lerde kalmıştır ${ }^{1}$. Tüm bu çalışmalar GSBL üreten gram negatif bakterilerin yol açtığı idrar yolu enfeksiyonlarının tedavisinde BLBLI'ların etkili olduğunu göstermektedir. Ancak bizim çalışmamızda E. coli'nin neden olduğu idrar yolu enfeksiyonlarında TZP direnci; \% 44,6; $K$. 
pneumoniae suşlarında da \%41 gibi oldukça yüksek oranlarda saptand1. Üriner sistem enfeksiyonlarında bu durum dikkate alınarak tedavi yönlendirilmelidir.

Üriner sistem enfeksiyonu dişındaki enfeksiyonlarda da TZP'nin etkin olduğunu gösteren çalışmalar mevcuttur. Gavin ve ark. ${ }^{8}$ idrar, kan, balgam ve yumuşak dokudan izole edilen GSBL pozitif bakterilerin neden olduğu enfeksiyonlarda TZP'nin etkinliğini incelemişler ve sonuçta; idrar yolu enfeksiyonu olan 6 hastanın tümünde TZP'1 duyarlı olarak bulurken idrar yolu dışı enfeksiyonu olan 11 hastanın 10'unda duyarlı olarak bulmuşlardır. Buna karşın ülkemizde yapılan bir çalışmada solunum yolu örneklerinden izole edilen GSBL pozitif izolatlarda TZP direnç oranı $\% 58,8$ olarak rapor edilmiştir. ${ }^{9}$ Bizim çalışmamızda TZP direnç oranları; trakeal aspirat ve yara/steril vücut sıvı örneklerinden izole edilen GSBL pozitif E. coli suşlarında sırasıyla; \% 47,6, $\% 41,8$ iken GSBL pozitif $K$. pneumoniae suşlarında sırasıyla; \% 44, \%35,4 şeklinde bulunmuştur. $\mathrm{Bu}$ sonuçlar bu tip enfeksiyonlarda etken olan GSBL pozitif bakterilere TZP'nin etkinliği konusunda şüphe uyandırmaktadır.

GSBL üreten bakterilerin neden olduğu kan dolaşım enfeksiyonlarının tedavisinde TZP tedavisinin yetersiz kaldığı ve karbapenemlerin daha etkili olduğunu bildiren çalışmalar bulunmakla birlikte bunun tersi sonuçlar gösteren çalışmalar da bulunmaktadır. ${ }^{10-14}$ Tamma ve ark. GSBL üreten gram negatif bakterilerin etken olduğu bakteriyemili hastalarda TZP tedavisi ile karbapenem tedavisi karşılaştırılmış ve TZP tedavi sonuçlarının daha başarısız olduğu gösterilmiştir. TZP tedavisi alan hastaların \%17'si ölümle sonuçlanırken, karbapenem tedavisi alan hastaların \%8' i ölümle sonuçlanmıştır. ${ }^{10}$ Rodriguez-Bano ve ark. ${ }^{11}$ GSBL pozitif E. coli'nin neden olduğu bakteriyemilerde karbapenem yerine TZP kullanımının da etkili olabileceğini bildirmişlerdir. Ancak bunun tam karşıtı olarak Varkadas ve ark. ${ }^{12}$ TZP kullanımın mortaliteyi artıracağını rapor etmişlerdir. Ülkemizden yapılan bir çalışmada ise karbapenem ve TZP kullanımının mortalite üzerindeki etkileri arasındaki fark anlamlı bulunmamıştır. $\mathrm{Bu}$ çalışmada ilaç etkinliği değerlendirilirken altta yatan risk faktörlerinin de göz önünde bulundurulması gerektiği bildirilmiştir. ${ }^{15}$ Bizim çalışmamızda GSBL pozitif E.coli suşlarında TZP direnci \%44,6 olarak bulunurken, imipenem direnci $\% 15,6$, ertapenem direnci ise \%8,4 saptand1. GSBL pozitif K.pneumaniae suşlarında ise TZP direnci \% 41 iken, imipenem ve ertapenem direnci $\% 7$ olarak saptandı. Elde ettiğimiz veriler incelediğimiz GSBL pozitif izolatlara karşı karbapenemlerin etkinliğinin TZP'ye göre oldukça yüksek olduğunu 
göstermektedir. Karbapenemler içerisinde daha geç kullanıma giren ertapenem dar spektrumlu olması, günde tek doz kullanım avantajı nedeni ile GSBL pozitif Enterobactericea enfeksiyonlarında tercih edilmektedir. ${ }^{16,17}$

Sonuç olarak; $\mathrm{Bu}$ çalışmada GSBL üreten $E$. coli ve $K$. pneumoniae suşlarında literatüre göre daha yüksek direnç oranları saptanmıştır. GSBL üreten Enterobacteriaceae suşlarının neden olduğu enfeksiyonlarda TZP'nin etkinliği konusunda yeterli çalışma bulunmamakta olup, bu enfeksiyonların tedavisinde TZP kullanımı ile ilgili bir belirsizlik söz konusudur. Mevcut çalışmalar, TZP'nin etkinliğinin enfeksiyonun yerine ve şiddetine göre değiştiğini göstermektedir. TZP sonuç bildirimi konusunda CLSI ve EUCAST arasında da fikir birliği bulunmamaktadır. Dolayısıyla bu konuda daha geniş kapsamlı çalışmalara ihtiyaç duyulmakta ve TZP sonuç bildiriminin yeniden değerlendirilmesi gerekmektedir.

\section{KAYNAKLAR}

1. Seo YB, Lee J, Kim YK, et al. Randomized controlled trial of piperacillin tazobactam, cefepime and ertapenem for the treatment of urinary tract infection caused by extendedspectrum betalactamase-producing Escherichia coli. BMC Infectious
Diseases. 2017;17:404. Doi: 10.1186/s12879-017-2502-x

2. Ofer-Friedman H, Shefler C, Sharma S, Tirosh A, Tal-Jasper R, Kandipalli D. Carbapenems Versus PiperacillinTazobactam for Bloodstream Infections of Nonurinary Source Caused by Extended- Spectrum Beta-LactamaseProducing Enterobacteriaceae. Infect Control Hosp Epidemiol. 2015;36(8):981-5.

3. De L'E'toile-Morel S, Cheng MP, Cheng AP, McDonald EG, Lee TC. Piperacillin-tazobactam use in GSBL Escherichia coli bacteremia:Should reporting be revised? JAMMI. 2018 3:1. Doi:10.3138/jammi.3.1.05.

4. Wayne P. Performance standards for antimicrobial susceptibility testing, 27th ed. CLSI supplement M100.Clinical and Laboratory Standards Institute; 2017.

5. Leclercq R, Canto'n R, Brown DF, et al. EUCAST expert rules in antimicrobial susceptibility testing. Clin Microbiol Infect. 2013;19(2):141-60.

6. Schuetz AN, Reyes S, Tamma PD. Point-Counterpoint: PiperacillinTazobactam Should Be Used To Treat Infections with Extended-SpectrumBeta-Lactamase-Positive Organisms. J 
Clin Microbiol. 2018;56(3). Doi: 10.1128/JCM.01917-17.

7. Guet-Revillet H, Tomini E, Emirian A, et al. Piperacillin/tazobactam as an alternative antibiotic therapy to carbapenems in the treatment of urinary tract infections due to extendedspectrum $\quad \beta$-lactamase-producing Enterobacteriaceae: an in silico pharmacokinetic study. Int $\mathbf{J}$ Antimicrob Agents. 2017;49(1):62-66.

8. Gavin PJ, Suseno MT, Thomson RB, et al. Clinical Correlation of the CLSI Susceptibility Breakpoint for Piperacillin-Tazobactam against Extended-Spectrum-_-Lactamase-

Producing Escherichia coli and Klebsiella Species. Antimicrob Agents Chemother. 2006:50(6):2244-47.

9. Şen P, Yula E, Demirdal T, Kaya S, Nemli SA, Demirci M. Solunum yollarından izole edilen genişlemiş spektrumlu ve indüklenebilir betalaktamaz üreten bakterilerin direnç oranları. Ortadoğu Tip Derg. 2017;9(4):170-176.

10. Tamma PD, Han JH, Rock C, et al. for the Antibacterial Resistance Leadership Group. Carbapenem Therapy Is Associated With Improved Survival Compared With Piperacillin-
Tazobactam for Patients With ExtendedSpectrum $\beta$-Lactamase Bacteremia. Treatment of GSBL Bacteremia. Clin Infect Dis. 2015;60:1319-25.

11. Rodri'guez-Baño J, Navarro MD, Retamar P, et al. b-lactam/b-lactam inhibitor combinations for the treatment of bacteremia due to extended-spectrum b-lactamase-producing Escherichia coli: a post hoc analysis of prospective cohorts. Clin Infect Dis. 2012;54(2):16774.

12. Vardakas KZ, Tansarli GS, Rafailidis PI, Falagas MB. Carbapenems versus alternative antibiotics for the treatment of bacteraemia due to Enterobacteriaceae producing extended-spectrum blactamases: a systematic review and meta-analysis. J Antimicrob Chemother. 2012;67(12):2793-803.

13. Retamar P, López-Cerero L, Muniain MA, Pascual Á, Rodríguez-Baño J,the GSBL-REIPI/GEIH Group. Impact of the MIC of Piperacillin-Tazobactam on the Outcome of Patients with Bacteremia Due to Extended-Spectrum-LactamaseProducing Escherichia coli. Antimicrob Agents Chemother. 2013;57(7):402-04. 14. Harris PN, Peleg AY, Iredell J, et al. Meropenem versus piperacillintazobactam for definitive treatment of 
bloodstream infections due to ceftriaxone non-susceptible Escherichia coli and Klebsiella spp (the MERINO trial): study protocol for a randomised controlled trial. BioMed Central. $2015 ; 16: 24$.

15. Sönmez U, Çalık Ş, Çayıröz MU, Olut AI, Arı A, Tosun S, Yiş R. Genişlemiş spektrumlu beta-laktamaz salgilayan Klebsiella pneumoniae ve Escherıchı coli'ye bağlı bakteriyemilerde mortalite ile ilişkili risk faktörlerinin belirlenmesi ve ampirik piperasilin tazobaktam ile karbapenem tedavisi sonuçlarının karşılaştırılması ANKEM Derg. 2018;32(1):1-8.

16. Kuzaytepe EÇ, Karaaslan A, Akın Y, Küçük N, Karataş Ö, Hacıseyıtoğlu D, Yüzüak SG, Şırınoğlu M Çocuklarda Ertapenem Tedavisinin GSBL Üreten Mikroorganizmaların Sebep Olduğu İdrar Yolu Enfeksiyonlarında Etkinlik ve Güvenilirliği. J Kartal TR. 2016;27(2):134-138

17. Keating GM, Perry CM. Ertapenem: a review of its use in the treatment of bacterial infections. Drugs. 2005;65:2151-78. 
Tablo 1. GSBL pozitif $E$. coli ve $K$. peumoniae suşlarının izole edildikleri klinik örneklere göre dağılımı ve TZP direnç oranları.

\begin{tabular}{|c|c|c|c|c|c|c|}
\hline \multirow{2}{*}{ Örnek Tipi } & \multicolumn{3}{|c|}{ E. coli } & \multicolumn{3}{|c|}{ K. pneumoniae } \\
\hline & $\begin{array}{c}\text { Duyarlı } \\
\text { n (\%) }\end{array}$ & $\begin{array}{c}\text { Dirençli } \\
\text { n (\%) }\end{array}$ & Toplam & $\begin{array}{c}\text { Duyarlı } \\
\text { n (\%) }\end{array}$ & $\begin{array}{c}\text { Dirençli } \\
\text { n (\%) }\end{array}$ & Toplam \\
\hline İdrar $(n=326)$ & $103(54,4)$ & $86(45,5)$ & 189 & $79(57,6)$ & $58(42,3)$ & 137 \\
\hline Kan $(n=85)$ & $31(57,4)$ & $23(42,5)$ & 54 & $18(\% 58,0)$ & $13(41,9)$ & 31 \\
\hline Trakeal aspirat $(n=46)$ & $11(52,3)$ & $10(47,6)$ & 21 & $14(56)$ & $11(44)$ & 25 \\
\hline Yara/steril vücut sıvısı $(n=91)$ & $25(58,1)$ & $18(41,8)$ & 43 & $31(64,5)$ & $17(35,4)$ & 48 \\
\hline Toplam $(\mathrm{n}=548)$ & $170(55,3)$ & $137(44,6)$ & 307 & $142(58,9)$ & $99(41)$ & 241 \\
\hline
\end{tabular}


Tablo 2. GSBL pozitif E. coli ve K. pneumoniae suşlarının karbapenem direnç oranları

\begin{tabular}{|c|c|c|c|c|c|c|c|}
\hline \multirow{2}{*}{ Örnek tipi } & \multicolumn{3}{|c|}{ E. coli } & \multicolumn{4}{|c|}{ K. pneumoniae } \\
\hline & $\begin{array}{c}\text { İmipenem } \\
\mathrm{n}(\%)\end{array}$ & $\begin{array}{c}\text { Ertapenem } \\
\mathrm{n}(\%)\end{array}$ & Toplam & $\begin{array}{c}\text { İmipenem } \\
\mathrm{n}(\%)\end{array}$ & $\begin{array}{c}\text { Meropenem } \\
\mathrm{n}(\%)\end{array}$ & $\begin{array}{c}\text { Ertapenem } \\
\mathrm{n}(\%)\end{array}$ & Toplam \\
\hline İdrar & $16(8,4)$ & $7(3,7)$ & 189 & $11(8)$ & $11(8)$ & $13(9,4)$ & 137 \\
\hline Kan & $8(14,8)$ & $5(9,2)$ & 54 & $1(3,1)$ & $1(3,2)$ & $1(3,2)$ & 31 \\
\hline Trakeal aspirat & $8(38)$ & $4(19,0)$ & 21 & $2(8)$ & $2(8)$ & $1(4)$ & 25 \\
\hline Yara/steril vücut sıvısı & $10(23,2)$ & $10(23,2)$ & 43 & $3(6,3)$ & $4(8,3)$ & $2(4,1)$ & 48 \\
\hline Toplam & $42(13,6)$ & $26(8,4)$ & 307 & $17(7)$ & $18(7,4)$ & $17(7)$ & 241 \\
\hline
\end{tabular}

